\title{
Um contexto em transformação político- pedagógico: a articulação entre uma escola regular e um centro de atendimento educacional especializado
}

\author{
Bárbara Martins de Lima Delpretto* \\ Bianca Campos Carlos dos Santos**
}

\begin{abstract}
Resumo
Partindo do pressuposto que as instituições regulares e centros de AEE-atendimento educacional especializado atuam na oferta obrigatória de serviços e recursos voltados para os alunos com deficiência, ambas devem estabelecer uma juntura capaz de favorecer o processo de escolarização desses alunos (MEC, 2008, 2009, 2010). Sendo assim, este artigo tem por objetivo relatar uma investigação sobre a articulação entre uma escola regular de ensino, com matrícula de alunos com deficiência na educação básica, e uma instituição conveniada para a oferta do serviço do AEE, compreendendo o papel de cada profissional na escolarização do aluno com deficiência na cidade de São Carlos (SP). A metodologia é a de estudo de caso com utilização de questionário semi estruturado (GIL, 1999). A partir das conclusões prévias observadas, compreende-se que as propostas de ambas as instituições são coesas à gestão organizacional adotada por cada uma. No entanto, no que tange a execução de projetos que requeiram comunicação extra institucional, vemos que estes não têm sido executados de forma efetiva às especificidades do aluno, de maneira que potencialize suas capacidades.
\end{abstract}

Palavras-chave: Educação Especial; Atendimento Educacional Especializado; Pessoas com deficiência.

\footnotetext{
* Professora no Centro Universitário para o Desenvolvimento do Alto Vale do Itajaí (UNIDAVI-SC). Itajaí, Santa Catarina, Brasil.

** Graduanda do Curso de Licenciatura em Educação Especial na Universidade Federal de São Carlos (UFSCar-SP). Atualmente trabalha na melhoria e na comercialização de software de ensino de banho, desenvolvido para pessoas com deficiência intelectual. Itajaí, Santa Catarina, Brasil.
} 


\title{
A pedagogical and political transformation in context: the relationship between a regular school and a specialized educational service center
}

\begin{abstract}
On the assumption that regular institutions and specialized educational service centres operate in specialized educational service mandatory bid for students target audience of special education, they must establish a relationship capable of facilitating the process of education of these students (MEC, 2008, 2009, 2010). Therefore, this article aims to report an investigation on the relationship between a regular school education with the registration of students with disabilities in basic education and an institution that offer specialized educational service, understanding the role of each professional in the education of a student with disabilities in the city of São Carlos (SP). The methodology is the case study with use of questionnaire (GIL, 1999). Regarding the preliminary conclusions from previous observation, it is understandable that the proposals of both institutions are cohesive to organizational management adopted by each one. However, regarding the execution of projects that require communication beyond the institution, we see that these have not been effectively implemented to the specificities of the students, in order to leverage their capabilities.
\end{abstract}

Keywords: Special education; Specialized educational service; People with disabilities.

\section{Introdução}

A Lei de Diretrizes e Bases da Educação Nacional, Lei no 9.394/96, no Art. 4º, salienta o dever do Estado com educação escolar pública, efetivado mediante a garantia de atendimento educacional especializado (AEE), de forma gratuita aos educandos com necessidades educacionais específicas, preferencialmente na rede regular de ensino. O serviço do AEE, voltado aos alunos com deficiência, transtornos globais do desenvolvimento e altas habilidades/superdotação, poderá ser ofertado em classes, escolas ou serviços especializados, sendo complementar ou suplementar a escolarização dos mesmos matriculados em classes comuns de ensino regular (MEC/ SEESP, 2008).

Neste contexto, percebe-se que é de competência dos professores, que atuam na sala de recursos multifuncionais em escolas regulares ou Centros de AEE (Resolução CNE/CEB nº 4/09), a elaboração e a execução do plano de AEE, em articulação com os demais professores do ensino regular, com a participação das famílias e em interface com os demais serviços setoriais da saúde, da assistência social, 
entre outros, necessários ao atendimento. Tal articulação entre os serviços e recursos da educação especial, que recaem sobre a ampliação do período escolar, é prevista com o objetivo de maximizar o desenvolvimento acadêmico e social dos respectivos alunos (Decreto nº 7.611/11).

Partindo do pressuposto que as instituições regulares e centros de atendimento educacional especializado atuam na oferta obrigatória do AEE para os alunos público alvo da educação especial, ambas devem estabelecer uma articulação capaz de favorecer o processo de escolarização desses alunos que frequentam o atendimento, de modo a fomentar a colaboração entre os profissionais que atuam na área.

Nesse sentido, essa investigação teve como objetivo geral analisar como ocorreu a articulação entre uma escola regular de ensino com matrícula de alunos com deficiência, na educação básica, e uma instituição conveniada para a oferta do serviço do AEE, a fim de compreender o papel de cada profissional na escolarização do aluno com deficiência, na cidade de São Carlos (SP). Desta forma, a pesquisa se detém na análise dos aspectos político-pedagógicos, observando a transformação da gestão escolar para a elaboração e viabilização de recursos pedagógicos acessíveis aos alunos com deficiência em sala de aula e em sala de recursos multifuncionais.

\section{Caracterização da Pesquisa}

A pesquisa em questão apresenta a metodologia de estudo de caso, por meio de aplicação de questionário semi estruturado (GIL, 1999) com os profissionais atuantes em duas instituições escolares da cidade de São Carlos (SP), sendo uma escola municipal de ensino básico, que apresenta matrícula de 15 alunos com deficiência e uma antiga escola especializada, recentemente conveniada à Secretaria de Educação, da cidade, como um Centro de Atendimento Educacional Especializado, com 62 alunos deficientes matriculados em diversas escolas públicas de ensino regular na localidade, nos períodos da manhã e tarde. A Escola Municipal será nomeada de ESCOLA l e a instituição nomeada de ESCOLA 2.

No total, foram entrevistados oito profissionais que atuam ou atuaram com alunos com necessidades educacionais específicas no ano de 2011, sendo quatro professores do ensino fundamental da ESCOLA 1 e outros quatro professores de educação especial da ESCOLA 2. O instrumento utilizado para a investigação com os sujeitos participantes abordou perguntas dissertativas que problematizaram a atuação destes profissionais na atual articulação entre ambas as instituições escolares.

Foram apresentadas as seguintes questões:

- Como é realizado o processo de inclusão do aluno com NEE na rede regular de ensino?

- Qual é o papel da educação especial? 
- O que é e como é desenvolvido o AEE?

- O AEE consta no PPP da instituição?

- Quantos alunos frequentam somente o AEE (não estão matriculados em sala de aula neste mesmo local)?

- Quais os impactos (positivos, negativos) na aprendizagem do(s) aluno(s) que frequenta $(\mathrm{m})$ o AEE?

- Como é feita adaptação dos conteúdos curriculares aos estudantes com NEE em sala comum?

- Quais são os profissionais envolvidos neste serviço?

- Como é a relação entre a instituição que o aluno tem matrícula em sala de aula e a instituição que oferece o AEE?

- Qual é a frequência do encontro entre os professores em ambas as instituições e que atuam com o(s) aluno(s) com necessidades educacionais específicas?

As duas primeiras questões pertencem a categoria "educação especial", sendo as demais pertencentes à categoria "atendimento educacional especializado."

Cada professor participante da pesquisa - no total oito sujeitos - teve sete dias para o preenchimento das questões dissertativas acima citadas. O preenchimento do questionário foi realizado no local de trabalho dos participantes da pesquisa, em um prazo total de trinta dias. Cada questão que compôs o questionário será analisada individualmente a seguir.

\section{A recente articulação entre duas instituições distintas atendendo concomitantemente aos alúnos com deficiência}

Segundo dados da United Nations Children's Fund - UNICEF (2011) existem hoje, no país, cerca de 24 milhões de pessoas com deficiência, sendo que 1,3 milhão têm idades entre 15 e 19 anos. Segundo o movimento apontado no período de 1998 a 2010, o número de matrículas de tais sujeitos da faixa etária indicada acima tem diminuído nas escolas especializadas e exclusivas - cerca de 75 mil matrículas - e crescido nas escolas regulares, com mais de 440 mil matrículas. A Tabela 1 retrata a 
transformação no quadro de matrículas no campo da educação especial.

Tabela 1 - Censo Escolar do ano 2010. Fonte: INEP/MEC, 2010.

Inclusão - Número de matrículas de adolescentes com deficiências em escolares regulares e escolas especiais no Brasil

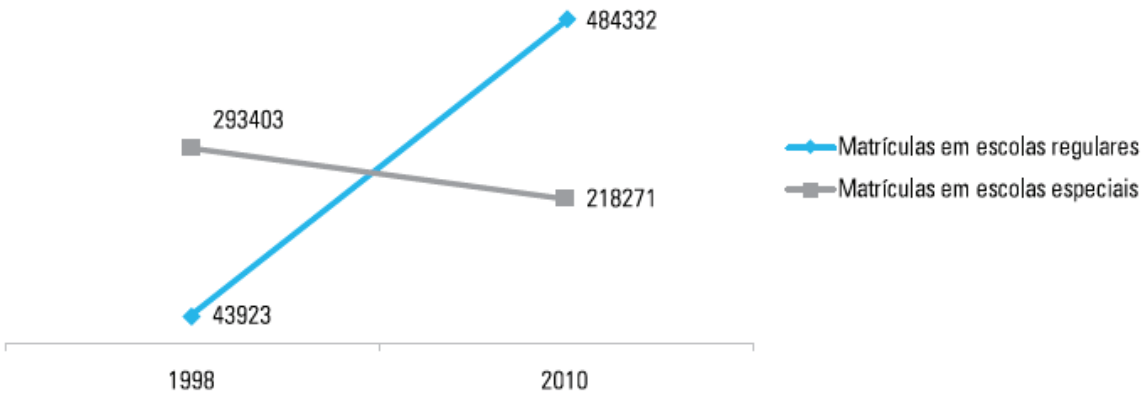

O movimento pela inclusão das pessoas com deficiência, transtornos globais do desenvolvimento e altas habilidades/superdotação, visto por políticas educacionais internacionais, tem se ampliado de modo acentuado, nas estratégias públicas nacionais, após a publicação do documento da Política Nacional de Educação Especial na Perspetiva da Educação Inclusiva (MEC, 2008). Dentre as normativas do documento, também amparadas legalmente, em especial, pelo Decreto n⿳o 7.611/1l e a Resolução CNE/CEB nº 4/09, está a defesa por um sistema público de ensino e de qualidade aos sujeitos da educação especial, os critérios e condições para o duplo FUNDEB - Fundo de Manutenção e Desenvolvimento da Educação Básica e de Valorização dos Profissionais da Educação, a necessidade de formação específica para a atuação em Educação Especial e a especificação do atendimento educacional especializado (AEE), como um dos serviços da educação especial a ser ofertado em escolas regulares ou Centros de Atendimento Educacional Especializado conveniados.

Com base neste contexto, cada estudante com necessidades educacionais específicas tem a possibilidade de, após matricular-se em uma escola regular de ensino, matricular-se concomitantemente no atendimento educacional especializado caso seja necessário. ${ }^{1}$ Para fins de financiamento da matrícula no AEE, tais alunos deveriam apresentar matrícula em uma das seguintes situações: matrícula em classe comum e em sala de recursos multifuncionais da mesma escola pública; matrícula em classe comum e em sala de recursos multifuncionais de outra escola pública; matrícula em classe comum e em centro de Atendimento Educacional Especializado de instituição de Educação Especial pública; matrícula em classe comum e em centro de Atendimento Educacional Especializado de instituições de Educação Especial comunitárias, confessionais ou filantrópicas sem fins lucrativos. 
Segundo dados publicados no Portal do Ministério da Educação, de 149 escolas regulares registradas no Censo Escolar do ano de 2011, da cidade de São Carlos (SP), e de um total de 52.530 distribuídas até 2010 em todo o país, na localidade há 14 salas de recursos multifuncionais implantadas em escolas públicas, sendo doze salas do tipo I e duas salas do tipo II (MEC/SECADI, 2011). O número de matrículas registradas no mais recente Censo Escolar (MEC/INEP, 2011) aponta 153 matrículas de alunos com necesidades educacionais específicas na rede regular, sendo 54 matrículas registradas também, no atendimento educacional especializado. ${ }^{2}$

Tendo em vista tais dados estatísticos e considerando as especificidades do município, neste artigo, explicitar-se-á as questões referentes a investigação sobre a articulação entre uma escola pública e um Centro de Atendimento Educacional Especializado em duas categorias: educação especial e atendimento educacional especializado.

\section{Categoria de análise: educação especial}

Sob a ótica da educação especial, na perspectiva da educação inclusiva, os alunos com deficiência devem ter condições de acesso e permanência no ambiente escolar. Partindo do pressuposto do acesso do aluno com necessidades educacionais específicos à sala de aula regular apenas pela efetivação da matrícula, Mendes (2006, p. 399) aponta que:

No geral, os estudos nacionais indicam que, mesmo para as poucas matrículas existentes, faltam aspectos básicos para garantir não apenas o acesso, mas a permanência e o sucesso desses alunos com necessidades educacionais especiais matriculados em classes comuns.

Subsidiados pela paráfrase, a questão número l (um) teve por objetivo investigar sobre o processo de inclusão, no que tange ao acesso e a permanência do aluno com deficiência na rede regular de ensino. Os participantes da ESCOLA 1 afirmaram que, segundo experiências de todos os participantes, a escolarização do aluno com necessidades educacionais específicas, em sala de aula, ocorreu sem qualquer tipo de conhecimento prévio do professor acerca das necessidades desse aluno. De acordo com as respostas, os participantes, mesmo com experiências pedagógicas em média de dez anos, garantem ainda haver demanda acentuada de capacitação anterior e, de forma contínua, para colaboração no trabalho com um aluno portador de necessidades educacionais especiais.

Entretanto, segundo todos os participantes da escola 2, o processo de inclusão do aluno com NEE, na rede regular de ensino, já era realizado de diferentes formas, uma vez que, ao efetuarem a matricula no AEE, os alunos já deviam estar matriculados e frequentando a escola regular de ensino. Já, ao serem incluídos na sala de aula regular por intermédio do Centro de AEE, os alunos com NEE passavam por uma avaliação de uma equipe multidisciplinar e do docente da sala de recursos multifuncionais, cuja análise fomenta a definição de estratégias de atuação pedagógica no plano complementar de ensino. 
A escola 2, ao tratar da escolarização das pessoas com deficiência, salientava que a inclusão vai além da inserção desse aluno em sala de aula, expandindo seus objetivos educacionais e envolvendo alguns profissionais de apoio em casos específicos. Logo, a promoção de uma nova proposta pedagógica possibilitaria a todos plena participação e autonomia, para que os alunos possam ter potencializadas suas capacidades e habilidades, resultando em um aprendizado significativo e funcional contextualizada as demandas individuais e ambientais.

Com referencia a questão número 2 (dois) da categoria Educação Especial - Qual é o papel da educação especial? - conforme quadro explicativo a seguir, notase uma distinção de ideias ao caracterizar a oferta e o serviço que cabe à Educação Especial e aos seus respectivos profissionais. Enquanto os participantes da ESCOLA 1 exemplificaram as práticas pedagógicas observadas no espaço da sala de aula regular, como um serviço de apoio, a ESCOLA 2 identificava tal atuação a partir da oferta do serviço do atendimento educacional especializado, como forma de escolarização do aluno com deficiência.

\begin{tabular}{|c|c|c|c|c|c|}
\hline \multirow{4}{*}{ 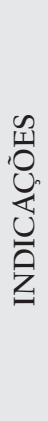 } & & ESCOLA 1 & \multirow{4}{*}{ 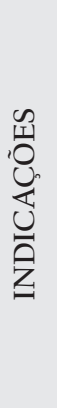 } & & ESCOLA 2 \\
\hline & 3 & $\begin{array}{l}\text { Auxiliar o professor } \\
\text { regente }\end{array}$ & & 3 & $\begin{array}{l}\text { Oferecer atendimento educacional } \\
\text { especializado de forma não substituta } \\
\text { à escolarização }\end{array}$ \\
\hline & 2 & Adaptar de atividades & & 1 & $\begin{array}{l}\text { Oferecer atendimento educacional } \\
\text { especializado de forma substitutiva }\end{array}$ \\
\hline & 1 & $\begin{array}{l}\text { Estimular } \\
\text { individualmente os } \\
\text { alunos com NEE em sala } \\
\text { de aula }\end{array}$ & & 1 & Escolarizar os alunos com NEE \\
\hline
\end{tabular}

Tabela 2 - Resumo das respostas obtidas na questão 2 da pesquisa

A partir do quadro, para que se haja uma análise clara e significativa dos dados apresentados, foi necessário expor as funções e responsabilidades da Educação Especial, apontadas pela legislação vigente. De acordo com o artigo no 59 da Lei de Diretrizes e Bases da Educação Nacional - LDB, Lei no 9.394/96, os sistemas de ensino devem assegurar aos alunos, com necessidades educacionais específicas, currículos, métodos, técnicas, recursos educativos e organização específicos, a possibilidade de terminalidade específica para aqueles que não podem atingir o nível exigido para a conclusão do ensino fundamental, concluindo em menor tempo o programa escolar, e contar com professores capacitados em salas comuns do ensino regular e para a oferta do atendimento educacional especializado.

Já, a Política Nacional de Educação Especial, na Perspectiva da Educação Inclusiva (2008), de modo específico, caracteriza a Educação Especial como modalidade de ensino responsável pela oferta do atendimento educacional 
especializado, assim como disponibilização dos demais recursos e serviços da mesma aos alunos com deficiência, transtornos globais do desenvolvimento e altas habilidades/superdotação.

Neste contexto, para a efetiva oferta do serviço da Educação Especial, são requeridas as práticas pedagógicas condizentes com as recomendações mencionadas, atendendo as peculiaridades e especificidades de cada aluno da Educação Especial. Desse modo, as atividades de auxílio aos professores, adaptações pedagógicas e atendimento individualizado aos alunos com NEE estão integradas à atuação da Educação Especial na medida em que seu papel está relacionado com a atuação do professor da rede regular de ensino; entretanto é necessário enfatizar que compete aos professores que atuam na sala de recursos multifuncionais ou centros de AEE a elaboração e a execução do plano de AEE, em articulação com os demais professores do ensino regular.

Portanto, verificou-se que a modificação do conceito da Educação Especial - antes definida como uma modalidade de ensino especial e substitutiva, e, atualmente, determinada como uma modalidade de ensino complementar ou suplementar a escolarização - e que oferta serviços e recursos aos alunos com deficiência - dentre eles o AEE, é de entendimento prático complexo, uma vez que a peculiaridade dos educandos em questão impõe ao sistema de ensino variadas formas de respostas educativas. Possibilitado legalmente a esse mesmo sistema de ensino autônomo para gerir tais estratégias, os professores da Educação Especial tendem a compreender claramente o plano político na oferta dos serviços e recursos da educação especial, mas a se sentir menos confiante para a alocação da "nova" educação especial no decorrer cotidiano da prática pedagógica.

\section{Categoria de análise: Atendimento Educacional Especializado}

$\mathrm{Na}$ categoria de análise "Atendimento Educacional Especializado", na questão apresentada "o que é e como se organiza o atendimento educacional especializado" notou-se, a partir das respostas obtidas, o escasso conhecimento a respeito do Atendimento Educacional Especializado por parte dos professores da ESCOLA 1. Uma vez que o conceito AEE ainda está em formação dentro e fora da comunidade escolar, na qual o aluno com NEE está incluído. Dentre as indicações realizadas, nenhum dos participantes indicou a função do AEE, sendo que um professor apontou desconhecer o serviço do atendimento educacional especializado, e outros três professores indicaram somente o lócus do AEE - a sala de recursos multifuncionais. A partir desses dados, podemos inferir que:

O AEE é uma iniciativa recente, proposta pelas políticas educacionais na área de Educação especial em perspectiva inclusiva, o que nos impede de tecer críticas a forma como estão sendo implantadas. Questionamos apenas se a Educação Especial, uma área de conhecimento e atuação, pode ser "limitada" ao que se denomina de AEE e como será a formação do professor do AEE com tantas e tão grandes 
tarefas no contexto da escola regular, visto que outras formas de atendimento gradativamente estão sendo fechadas pelo governo. (MAGALHÃES, 2011, p. 11)

Considerado um serviço complementar ou suplementar, o AEE é de competência dos professores que atuam na sala de recursos multifuncionais ou centros de $\mathrm{AEE}$, em articulação com os professores do ensino regular (RESOLUCÃO CNE/CEB no 4/09). Coerente com tal definição, a ESCOLA 2 indicou que cabe ao atendimento educacional especializado organizar e disponibilizar recursos e serviços pedagógicos (4), promover o apoio necessário para favorecer os alunos com necessidades educacionais especiais (2), e auxiliar na aprendizagem dos alunos nas salas regulares (1).

Logo, a construção do conceito e da forma de oferta do serviço do Atendimento Educacional Especializado como um dos serviços da Educação Especial e que não substitui a escolarização regular, ainda é recente e encontra-se em um processo evolutivo, na medida em que os profissionais envolvidos estão começando a vivenciar as tais práticas. Tal experiência vem proporcionar não só a criação de um novo conceito, mas também a expansão da abordagem pedagógica que se tinha da Educação Especial.

Ao abordar uma substituição por parte dos serviços da Educação Especial não podemos deixar de citar as atuais - e errôneas-interpretações de integração do aluno com NEE na rede regular de ensino, que visam apenas o desenvolvimento na socialização deste. A partir dessa significação ao processo de inclusão escolar, podese observar a substituição do serviço de caráter pedagógico para uma educação cuja normalização e integração são os reais objetivos definidos.

Questiona-se então a qual caráter vem sendo empregado o atendimento educacional especializado nos diferentes ambientes ilustrados nesta pesquisa, uma vez que os profissionais envolvidos discordam em uma questão de execução e organização do AEE com o mesmo público, os mesmos sujeitos. Assim, foi notável a ruptura de ideias e de opiniões relatados pelos participantes, uma vez que não há concordância entre os conceitos apresentados pelos profissionais da escola l e da escola 2 sobre as funções do AEE.

Com relação aos profissionais envolvidos na oferta do AEE, ambas as instituições apontaram haver a participação de toda comunidade escolar (professores, psicólogos, funcionários, entre outros). No total de indicações, foram sete diferentes personagens indicados pela ESCOLA 1 na execução do AEE (professor, psicólogo, fonoaudiólogo, fisioterapeuta, médico, pais e/ou responsáveis, gestores), e quatro da ESCOLA 2 (professor, psicólogo, gestores e pais e/ou responsáveis).

Sobre a definição política e pedagógica do papel da educação especial, no Artigo no 29 da Resolução CNE/CEB n⿳⺈ 4/09, a Educação Especial é definida como uma modalidade transversal, ofertada em todos os níveis, etapas e modalidades de 
ensino e deve estar inserida no Projeto Político Pedagógico da instituição; todavia ao analisarmos as respostas referentes à questão "O AEE consta no PPP da instituição de ensino?" é possível perceber o descumprimento de tal orientação.

Um dos participantes da escola 1 afirmou desconhecer a descrição do AEE no Projeto Político Pedagógico da instituição de ensino, enquanto os demais apresentaram respostas objetivas, revelando que a educação especial é tratada de forma superficial (3). Logo, o distanciamento das referências previstas no PPP e a prática educacional, uma vez que o conteúdo (na íntegra) de tal documento é desconhecido pelos profissionais que deveriam ter construído o mesmo.

Segundo Libâneo (2005), toda a equipe escolar deve (ria) estar envolvida no processo do planejamento e execução do projeto pedagógico da escola, uma vez que este documento compreende a manifestação das práticas educativas propostas pela gestão pedagógica. A partir do contexto investigado, nos deparamos com a disseminação dos objetivos organizacionais do Projeto Político Pedagógico, em uma realidade descentralizada, na qual os saberes pedagógicos não são compartilhados entre os educadores em busca do sucesso efetivo de toda uma instituição. Neste sentido, tal documento tende a não vigorar como "instrumento concreto de mudanças institucionais e do comportamento e das práticas dos professores" (LIBÂNEO, 2005, p. 357).

$\mathrm{Na}$ escola 2, todos os participantes limitaram-se em afirmar que o AEE consta no Projeto Político Pedagógico da instituição, sem maiores esclarecimentos sobre o aprofundamento do assunto no documento.

No que tange a questão "quais são os impactos (positivos, negativos) na aprendizagem do(s) aluno(s) que frequenta(m) o AEE?", os profissionais atuantes da escola 1, ou seja, do ensino regular, focam no atendimento individualizado de ensino para um melhor desenvolvimento cognitivo do aluno com NEE (2), além de indicar a possibilidade de obter um melhor rendimento do aluno (2) e colaborar no processo de socialização do mesmo (1). Entre os pontos negativos, foram apontados a falta de preparo da comunidade escolar (1), a falta de contato entre os profissionais do AEE (1) e o cansaço dos alunos que frequentam o AEE no turno contrário (l).

A análise dos pontos negativos apresentados demonstrou a frustração dos professores da rede regular de ensino, ao citarem a falta de preparo da comunidade escolar, atribuindo a si mesmos uma inabilidade por não proporcionarem um processo de ensino-aprendizagem de maneira assídua e objetiva, por ainda estarem norteados por práticas pedagógicas incertas, mas operantes segundo relatos. Os participantes, ainda, revelam que os alunos chegam cansados à escola, consequência da carga horária dobrada do aluno com NEE, uma vez que, na parte da manhã, ele encontra-se em AEE e a tarde no ensino regular (ou vice e versa).

Dentre os pontos positivos da empregabilidade do AEE, destaca-se a utilização dos conceitos de atendimento individualizado com o atendimento 
especializado como sinônimos. Enquanto que o atendimento educacional especializado tem vertentes legais destacadas pelas políticas públicas como um serviço da Educação Especial que ocorre em sala de recursos multifuncionais, o atendimento individualizado ou a individualização do ensino se refere à resposta da escola às necessidades individuais e/ou especiais dos alunos, no qual todos devem ser assistidos, parte por meio da construção coletiva do conhecimento num ambiente comum de aprendizagem, parte de modo específico, considerando as experiências anteriores de cada um, bem como seus ritmos de aprendizado.

Este planejamento deve ser feito de modo flexível para que, ao considerar as necessidades listadas, o professor possa estabelecer seus objetivos, facilitando assim o processo de elaboração do seu plano de ensino do atendimento educacional especializado. Esta flexibilidade da execução, aliada ao conceito que as participantes têm sobre o Atendimento Educacional Especializado, resulta em atribuições de responsabilidades adequadas e pertinentes ao contexto educação inclusiva.

$\mathrm{Na}$ escola 2, enquanto três participantes optaram por não responder a questão, uma participante afirmou que tais impactos são "variáveis", dependendo de como o aluno reage ao atendimento. Logo, a questão discutida foi "o que estes educadores esperam do AEE?", pois a partir das expectativas definidas sob o serviço oferecido é que serão determinadas as estratégias pedagógicas a serem utilizadas no contexto analisado. A resposta para esta pergunta implica uma série de fatores sociais, ambientais e históricos impostos a cada um dos contextos abordados fomentando uma reforma nos valores éticos, políticos e pedagógicos, de forma a promover o acesso igualitário a uma educação de qualidade, por meio de adequações no currículo, adaptações físicas e estruturais, implantação de materiais pedagógicos específicos e capacitação da comunidade escolar, garantindo o efetivo funcionamento da articulação entre educador especial e professor da sala regular.

Na questão "Como é feita adaptação dos conteúdos curriculares aos estudantes com NEE em sala de aula comum?", metade dos participantes da ESCOLA 1 mencionou que as mesmas são feitas pelas professoras com o auxílio da educadora especial da escola e, a outra metade afirmou que as adaptações eram feitas exclusivamente pelas professoras da classe regular, que utilizam a "intuição" para oferecer ao aluno o que acham que precisam; as mesmas revelam que não são todos os conteúdos curriculares que são passíveis de adaptação e, por esta razão, são suprimidos do currículo.

Já, ao serem questionadas quanto às adaptações curriculares, as participantes da ESCOLA 2 mencionaram que os conteúdos curriculares são diversos, abrangendo diferentes níveis de compreensão/desempenho dos alunos, além disso, as atividades são exploradas de acordo com as possibilidades e interesses de cada aluno. A compilação das respostas obtidas, bem como o número de indicações estão descritas no quadro a seguir. 
Tabela 3 - Resumo das respostas obtidas na questão 5 da pesquisa:

\begin{tabular}{llll}
\hline & $\begin{array}{l}\text { ESCOLA l } \\
\text { De acordo com os } \\
\text { objetivos definidos pela } \\
\text { educadora especial }\end{array}$ & $\begin{array}{l}\text { ESCOLA 2 } \\
\text { De acordo com o estágio }\end{array}$ & $\begin{array}{l}\text { De acordo com o estágio de } \\
\text { desenvolvimento da aprendizagem } \\
\text { do aluno }\end{array}$ \\
& $\begin{array}{l}\text { de desenvolvimento da } \\
\text { aprendizagem do aluno } \\
\text { De acordo com as } \\
\text { pesquisas na área }\end{array}$ & \\
\hline
\end{tabular}

A partir do quadro acima, percebe-se a ausência de uma proposta coesa entre ambos profissionais de ensino no que tange ao planejamento escolar. Consequentemente, o aluno com NEE percorre por diferentes "fases" no desenvolvimento do processo de ensino e de aprendizagem, uma vez que tal processo sofre rupturas devido à proposta curricular divergente de cada uma das instituições frequentadas.

A carência de articulação das práticas pedagógicas previamente construídas, por sua vez, "empobrece" a atuação dos profissionais da educação, interferindo diretamente na qualidade do processo ensino e de aprendizagem ao qual o aluno está exposto. Além disso, resultaram no processo inconsistente do objetivo de expandir as oportunidades de aproveitamento dos alunos com necessidades educacionais específicas, visto que limitam as oportunidades da educação as deduções pessoais e "achismos".

Para complementar tal discussão, os professores foram questionados quanto à atual relação entre a instituição regular de ensino e o Centro de Atendimento Educacional Especializado. Os participantes da ESCOLA l afirmam que tal relação é inexistente (4), e os participantes da ESCOLA 2 relatam que essa relação ocorreu por meio da colaboração dos professores da rede regular (por meio de formação continuada) (3) e limitando-se no apoio na produção de materiais didáticos e pedagógicos (4).

Por fim, os relatos obtidos por meio da questão "Qual é a frequência do encontro entre os profissionais em ambas as instituições e que atuam com o(s) aluno(s) com necessidades educacionais específicas?" a ESCOLA l reafirmou que tal articulação é inexistente. Já as profissionais da ESCOLA 2 alegaram que os encontros acontecem quando necessário, afirmaram, ainda, que a instituição promove tal articulação. No final de 2011, segundo os relatos, não houve nenhum encontro durante o ano. 


\section{Conclusão}

Durante o processo da coleta de dados, assim como nas outras fases da pesquisa, houve abertura das instituições participantes, contribuindo de maneira significativa para o desenvolvimento da atividade. Em sua maioria, as participantes responderam às questões sem apresentarem maiores dificuldades.

A respeito dos dados coletados, ricos em termos de encaminhamentos pedagógicos, no que tange a atual forma de organização da modalidade de ensino da educação especial, em específico na oferta do serviço do Atendimento Educacional Especializado, ambas as instituições de ensino apresentaram domínio político, uma vez que possuem conhecimento sobre algumas implicações do Projeto Político Pedagógico, de liberações legais e do regime de colaboração entre diferentes esferas, entre outros.

No que se refere à esfera pedagógica, entretanto, vimos que a forma de oferta do AEE ainda é de recente disposição no sistema de ensino, e que tal complexidade é ampliada quando falamos da escolarização de um mesmo alunado da educação especial, por sua vez, atendido concomitantemente em duas instituições: uma oferta os serviços regulares e obrigatórios para ensino, e a outra instituição complementando ou suplementando tal processo escolar.

Vimos que, diante desse contexto, e, a partir do exemplo investigado, a articulação de uma escola regular e um centro de atendimento educacional especializado ainda não possui as afinidades necessárias ao planejamento para uma significativa individualização do ensino para os alunos com deficiência. Muitos docentes ainda se sentem inseguros em uma intervenção conjunta diante das especificidades dessa articulação, assim como das necessidades educacionais dos alunos em questão.

Sendo assim, a proposta de ambas as instituições, de novo particular, é coesa à gestão organizacional adotada respectivamente por cada uma; quando falamos em uma proposta interinstitucional, por sua vez, esta não vem sendo adaptada de forma efetiva às especificidades do aluno com NEE, de maneira que potencialize suas capacidades, considerando que a aplicabilidade destas práticas exige a articulação da sala de aula regular e a sala de AEE, visando o processo contínuo de ensino e de aprendizagem.

Ao observar as práticas pedagógicas utilizadas em ambos os espaços educacionais, notamos uma carência de recursos estimulantes, pois muitas das atividades aplicadas ainda estão "engessadas" a uma proposta que se limita no uso de materiais diferenciados ao ambiente escolar e que geram, segundo relatos, um desinteresse por parte do aluno com NEE, uma vez que tem sido fomentada de forma similar, e não complementar, às práticas em sala de aula. Percebemos a necessidade de ampliar as discussões ainda mais específicas relacionadas à oferta e desenvolvimento 
do Atendimento Educacional Especializado, a fim de promover uma reflexão das propostas educacionais oferecidas atualmente por parte das instituições de ensino.

\section{Referências}

BRASIL, Decreto n. 9 7.611, de 17 de novembro de 2011, Dispõe sobre a educação especial, o atendimento educacional especializado e dá outras providências. Brasília, DF, 2011.

BRASIL, Resolução n’. 4, de 22 de outubro de 2009, Institui Diretrizes Operacionais para o Atendimento Educacional Especializado na Educação Básica, modalidade Educação Especial. Diário Oficial da União. Brasília, DF, 2009.

BRASIL. Ministério da Educação. Secretaria de Educação Especial. Política Nacional de Educação Especial na perspectiva da educação inclusiva. Brasília, DF: MEC/SEESP, 2008.

BRASIL, Lei de Diretrizes e Bases da Educação Nacional. Lei no . 9394/96 de 20 de dezembro de 1996. Estabelece as diretrizes e bases da educação nacional. Diário Oficial da União. Brasília, DF, 23 de dez., 1996.

BRASIL, Ministério da Educação. Constituição da República Federativa do Brasil. Brasília, DF, 1988.

Fundo Nacional de Desenvolvimento da Educação. Portaria Interministerial no 1.809 , de 28 de dezembro de 201l. Define e divulga os parâmetros anuais de operacionalização do Fundeb para o exercício de 2012. Brasília: FNDE/MEC, 2011.

GIL, A. C. Métodos e técnicas de pesquisa social. São Paulo: Atlas, 1999.

FUSARI, J. C. Planejamento educacional e a prática dos educadores. Ande, São Paulo, n. 8, p. 32-35, 1984.

MENDES, E. G. A radicalização do debate sobre inclusão escolar no Brasil. Revista Brasileira de Educação Especial. Rio de Janeiro. v.1l, n.33, set./dez.2006.

LIBÂNEO, J. C.; OLIVEIRA J. F.; TOSCHI M. S.; Educação escolar: políticas estrutura e organização. 2. ed. São Paulo: Cortez, 2005. (Coleção Docência em Formação)

GLAT, R; OLIVEIRA, E. da S. G. Adaptações Curriculares. Relatório de consultoria técnica, projeto Educação Inclusiva no Brasil: Desafios Atuais e Perspectivas para o Futuro. Banco Mundial, 2003. Disponível em:〈http://www.cnotinfor.pt/inclusiva〉. Acesso em: dez. 2003.

BAPTISTA, C. R. Ação pedagógica e educação especial: para além do AEE. VI Seminário Nacional de Pesquisa em Educação Especial: Prática Pedagógica na Educação Especial: multiplicidade do atendimento educacional especializado. Nova Almeida Serra, 2011.

MAGALHÃES, R. C. B. P. Educação Especial e Atendimento Educacional Especializado (AEE): expressões do contexto da educação inclusiva brasileira. VI Seminário Nacional de Pesquisa em Educação Especial: Prática Pedagógica na Educação Especial: multiplicidade do atendimento educacional especializado. Nova Almeida Serra, 2011. 


\section{Notas}

${ }^{1}$ Segundo orientações do Ministério da Educação, a oferta do atendimento educacional especializado é obrigatória ao sistema de ensino, mas condicionada a avaliação do educando com necessidades educacionais específicas e a elaboração do plano prévio de atendimento.

${ }^{2}$ No Estado de São Paulo, no município de São Carlos, o valor por aluno no atendimento educacional especializado é de R \$3.168,45 (FNDE, 2011)

${ }^{3}$ Neste artigo, compreende-se por adaptação, ou flexibilização curricular, o processo de modificações do planejamento, objetivos, atividades e formas de avaliação, no currículo como um todo, ou em aspectos dele, para acomodar os alunos com necessidades especiais (GLAT, 2003, p. 3).

\section{Correspondência}

Bárbara Martins de Lima Delpretto - Rua João Bim, n. 1520, Apto 301, CEP: 14090-340, Bairro Jardim Paulistano, Ribeirão Preto - São Paulo, Brasil.

E-mail: delpretto@gmail.com - bianca.educadora@gmail.com

Recebido em 11 de maio de 2012

Aprovado em 21 de junho de 2013 
